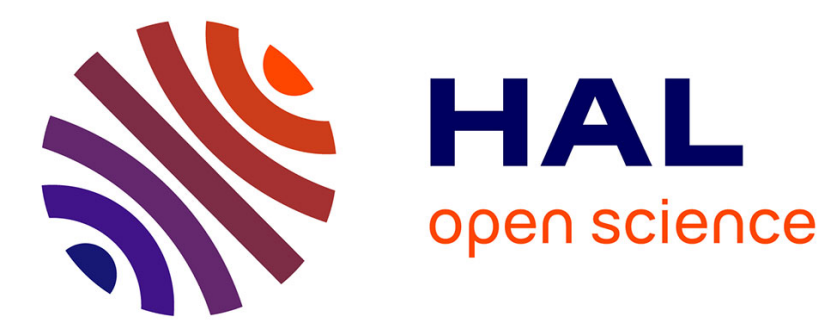

\title{
Intubation in the ICU: we could improve our practice
}

Audrey de Jong, Boris Jung, Samir Jaber

\section{To cite this version:}

Audrey de Jong, Boris Jung, Samir Jaber. Intubation in the ICU: we could improve our practice.

Critical Care, 2014, 18, 10.1186/cc13776 . hal-02549665

\section{HAL Id: hal-02549665 \\ https://hal.umontpellier.fr/hal-02549665}

Submitted on 21 Apr 2020

HAL is a multi-disciplinary open access archive for the deposit and dissemination of scientific research documents, whether they are published or not. The documents may come from teaching and research institutions in France or abroad, or from public or private research centers.
L'archive ouverte pluridisciplinaire HAL, est destinée au dépôt et à la diffusion de documents scientifiques de niveau recherche, publiés ou non, émanant des établissements d'enseignement et de recherche français ou étrangers, des laboratoires publics ou privés. 


\title{
REVIEW
}

\section{Intubation in the ICU: we could improve our practice}

\author{
Audrey De Jong, Boris Jung, Samir Jaber* \\ This article is one of ten reviews selected from the Annual Update in Intensive Care and Emergency Medicine 2014 and co-published as a series \\ in Critical Care. Other articles in the series can be found online at http://ccforum.com/series/annualupdate2014. Further information about the \\ Annual Update in Intensive Care and Emergency Medicine is available from http://www.springer.com/series/8901.
}

\section{Introduction}

Airway management is a commonly performed procedure in the intensive care unit (ICU). Hypoxemia and cardiovascular collapse represent the initial and most serious life-threatening complications associated with difficult airway access, both in emergency intubation in the critically ill [1]-[4] and in planned intubations (e. g., scheduled surgery or invasive procedures) [5]. To prevent and limit the incidence of life-threatening complications following intubation, several pre-oxygenation techniques and intubation algorithms have been entertained.

The objectives of the present chapter are to:

1) describe new tools (e. g., the MACOCHA Score) to better identify patients at high-risk of difficult intubation and related complications;

2) describe new strategies for improving pre-oxygenation before intubation (e. g., continuous positive airway pressure [CPAP] or non-invasive ventilation [NIV]);

3) propose an intubation bundle (the Montpellier-ICU intubation algorithm) to limit complications related to the intubation procedure;

4) report recent data on the role of videolaryngoscopes in the ICU; and, finally,

5) propose an algorithm for secure airway management in the ICU (The Montpellier-airway ICU algorithm).

\section{Which patients are 'at risk' of complications during intubation?}

All ICU patients could be considered at risk of complications during intubation. The main indication for intubation in the ICU is acute respiratory failure [1]-[4]. In these cases, the risk of hypoxemia and cardiovascular collapse during the intubation process (often crucial) is particularly elevated (15 to $50 \%$ [3]. Respiratory muscle

*Correspondence: s-jaber@chu-montpellier.fr

Intensive Care Unit, Anesthesia and Critical Care Department, Saint Eloi Teaching

Hospital, University Montpellier 1, 34295 Montpellier, France weakness ('ventilatory insufficiency') and gas exchange impairment ('respiratory insufficiency') are often present. It is thus worth anticipating that life-threatening complications may occur during intubation [6]. Obesity and pregnancy are the two main situations where functional residual capacity (FRC) is decreased and where the risk of atelectasis is increased leading to hypoxemia [6]. Other 'at risk' patients include those who cannot safely tolerate a mild degree of hypoxemia (epilepsy, cerebrovascular disease, coronary artery disease, sickle cell disease, etc. ...). Finally, patients considered to be 'difficult to intubate', in particular require adequate pre-oxygenation [7].

\section{How to identify risk factors for difficult intubation in the ICU?}

Although several predictive risk factors and scores for difficult intubation have been identified in anesthesia practice, until recently no (a priori) clinical score had been developed for ICU patients. However, a recent study assessed risk factors for difficult intubation in the ICU [3] and developed a predictive score of difficult intubation, the MACOCHA score, which was then externally validated. The main predictors of difficult intubation were related to the patient (Mallampati score III or IV, obstructive sleep apnea syndrome, reduced mobility of cervical spine, limited mouth opening), the pathology (coma, severe hypoxia) and the operator (nonanesthesiologist) (Table 1). By optimizing the discrimination threshold, the discriminative ability of the score is high. In order to reject difficult intubation with certainty, a cut-off of 3 or greater seems appropriate, providing an optimal negative predictive value $(97 \%$ and $98 \%$ in the original and validation cohorts, respectively) and sensitivity $(76 \%$ and $73 \%$ in the original and validation cohorts, respectively). The MACOCHA score enables patients at risk of difficult intubation to be identified and further studies are needed to determine whether calculating this score before each intubation could help 
Table 1 MACOCHA score calculation worksheet

\begin{tabular}{lc}
\hline & Points \\
\hline Factors related to patient & 5 \\
Mallampati score III or IV & 2 \\
Obstructive sleep apnea syndrome & 1 \\
Reduced mobility of cervical spine & 1 \\
Limited mouth opening $<3 \mathrm{~cm}$ & \\
Factors related to pathology & 1 \\
$\quad$ Coma & 1 \\
Severe hypoxemia $(<80 \%)$ & \\
Factor related to operator & 1 \\
$\quad$ Non-anesthesiologist & 12 \\
\hline Total
\end{tabular}

Coded from 0 to $12,0=$ easy, $12=$ very difficult

reduce the incidence of difficult intubations and related complications.

Of note, the Intubation Difficulty Scale (IDS) is a quantitative scale of intubation difficulty, which can be useful for objectively comparing the complexity of endotracheal intubation, but $a$ posteriori and not a priori [21].

\section{How to improve pre-oxygenation before intubation?}

Spontaneous ventilation

Several maneuvers in spontaneous ventilation (e. g., 3-8 vital capacities vs 3 minutes tidal volume breathing) exist to improve pre-oxygenation before intubation and seem to be almost equally effective [8]. Some technical details, however, can make a significant difference. First, the clinician needs to make sure that the facemask properly fits the patient's facial morphology. Second, fresh gas flow needs to be set at a high range to homogenize ventilation through the lungs and to decrease the impact of leaks [9], [10]. Third, leaks should be avoided and diagnosed either by a flaccid reservoir bag or by the absence of a normal capnograph waveform, because leaks impair the efficacy of pre-oxygenation.

End-tidal oxygen concentration $\left(\mathrm{EtO}_{2}\right.$ in \%) is available as a surrogate for oxygen alveolar pressure $\left(\mathrm{PAO}_{2}\right)$ which reflects, in part, the oxygen reserve in the lungs; the target commonly adopted is $90 \%$ [11]. This target is reached more quickly when pure oxygen is administered. Although the clinician must be aware of the potential complication of de-nitrogenation-induced atelectasis, the benefit of reaching an end-inspiratory oxygen fraction of $90 \%$ before attempting intubation outweighs the risk of developing atelectatic-related hypoxia in 'at risk' patients.

In critically ill patients, the advantage of a prolonged period of pre-oxygenation has not been clearly demonstrated. Most such patients present with acute respiratory failure with a certain amount of shunt, a reduced FRC, and do not respond to administration of oxygen as well as patients scheduled for surgery [12]. Mort et al. demonstrated a moderate increase in arterial oxygen pressure $\left(\mathrm{PaO}_{2}\right)$ after $4 \mathrm{~min}$ of oxygen therapy before intubation (from 62 to $88 \mathrm{mmHg}$ before and after oxygen therapy) [12]; despite pre-oxygenation, half of the 34 patients included in the study experienced severe hypoxia during intubation.

\section{Position}

Patient position is an important factor and limits the decrease in FRC. Studies have reported that pre-oxygenation in the semi-sitting position or in the $25^{\circ}$ head-up position can achieve higher $\mathrm{PaO}_{2}$. It may also prolong the time to hypoxemia in obese patients scheduled for surgery [13], [14]. To our knowledge, thus far only one study, performed in non-obese patients scheduled for surgery, has reported a beneficial impact of semi-sitting $\left(20^{\circ}\right.$ head up) during pre-oxygenation in terms of time to desaturation [15]. This position seems not to be beneficial in pregnant patients, probably because of the gravid uterus constraining the diaphragm in its upper position and because of the detrimental effect of the sitting position on vena caval back flow [16]. In the critically ill, there are so far no pre-oxygenation studies evaluating the semi-sitting versus the supine positions.

\section{Non-invasive ventilation with positive pressure}

Positive end-expiratory pressure (PEEP) with high-flow oxygen has been evaluated as a pre-oxygenation method in the morbidly obese. The aim of positive pressure used as a pre-oxygenation method is to increase the proportion of aerated lung, thereby limiting the decrease in FRC. This limitation in FRC decrease will result in an increase in lung oxygen stores, and may also help keep the closing capacity below the FRC. The closing capacity is the volume of air at which airways begin to close during expiration. The volume of air between the closing capacity and the residual volume is called the closing volume.

The first study was performed in the early 2000s and found that applying $7 \mathrm{cmH}_{2} \mathrm{O}$ of CPAP for 3 minutes did not prolong time to desaturation in morbidly obese women [17]. Important limitations of this study were the absence of ventilation between the onset of apnea and intubation, and the relative brevity of the pre-oxygenation (only 3 minutes). Later studies, however, showed a benefit of applying CPAP with oxygen during pre-oxygenation in morbidly obese patients [18], [19]. Compared to $\mathrm{O}_{2}$ alone, CPAP of $10 \mathrm{cmH}_{2} \mathrm{O}+\mathrm{O}_{2}$ for $5 \mathrm{~min}$ increased the time to desaturate and reduced the amount of atelectasis following intubation [18], [19]. Immediately after intubation, the amount of atelectasis measured by computed tomography (CT) was $10 \%$ in the oxygen group compared to only $2 \%$ in the $10 \mathrm{cmH}_{2} \mathrm{O}$ PEEP group [18]. 
In a landmark study of morbidly obese patients, our group showed that NIV using a pressure support ventilation (PSV) level of $8 \mathrm{cmH}_{2} \mathrm{O}$ and PEEP of $6 \mathrm{cmH}_{2} \mathrm{O}$ for 5 minutes was safe, feasible, and efficient [20]. We reported that $95 \%$ of patients could reach the endexpiratory oxygen fraction target of $90 \%$ with NIV compared to $50 \%$ in the oxygen group [20]. The impact of the combination of both semi-sitting position and NIV in obese and non-obese surgical patients needs to be evaluated.

Pre-oxygenation with NIV in pregnant patients has never been formally evaluated, as it may be harmful because of the risk of aspiration in this patient population.

NIV as a pre-oxygenation maneuver has also been evaluated in critically ill patients; our group reported its benefits compared to administration of oxygen alone [21]. Indeed, in a randomized controlled trial including hypoxemic patients, the incidence of severe hypoxemia $\left(\mathrm{SpO}_{2}<80 \%\right)$ within 30 min after intubation was $7 \%$ in the NIV group (PSV 5-15 $\mathrm{cmH}_{2} \mathrm{O}$, PEEP 5-10 $\mathrm{cmH}_{2} \mathrm{O}$, $\mathrm{FiO}_{2}=100 \%$ ), compared to $42 \%$ in the oxygen group. To perform NIV for 3 to $5 \mathrm{~min}$ in critically ill patients, the facial mask available in every ICU room is adequate. The patient should be in the semi-sitting position, $\mathrm{FiO}_{2}$ set at $100 \%$, inspiratory pressure set to observe a tidal volume of 6 to $10 \mathrm{ml} / \mathrm{kg}$ and respiratory rate of 10 to 25 cycles/ min. The duration of the procedure usually corresponds with the time needed to prepare the drugs and equipment for intubation. NIV was included in a bundle and was associated with a decrease in life-threatening hypoxemia following intubation in a multicenter study [1], [2] (Table 2).

\section{Recruitment maneuver}

As discussed earlier, the rationale of use NIV during preoxygenation is to recruit lung tissue available for gas exchange: 'Open the lung' with the PSV and 'keep the lung open' with PEEP, which limits alveolar de-recruitment. Conversely, the combination of de-nitrogenation (with $100 \% \mathrm{O}_{2}$ ) and the apneic period associated with the intubation procedure can dramatically decrease the aerated lung volume ratio, thereby causing atelectasis. In obese patients pre-oxygenated without positive pressure, the proportion of atelectasis following intubation can represent $10 \%$ of the total lung volume [18]. One option to limit alveolar de-recruitment after intubation is to ventilate the patient using a bag-valve balloon. However, it is not possible to measure the pressure delivered when patients are ventilated using this method.

A recruitment maneuver (RM) consists of a transient increase in inspiratory pressure. Several maneuvers exist, but the one best described in this situation consists of applying a CPAP of $40 \mathrm{cmH}_{2} \mathrm{O}$ for 30 to $40 \mathrm{~s}$ [22] - [24]. In
Table 2 The Montpellier-ICU intubation algorithm, adapted from [2]

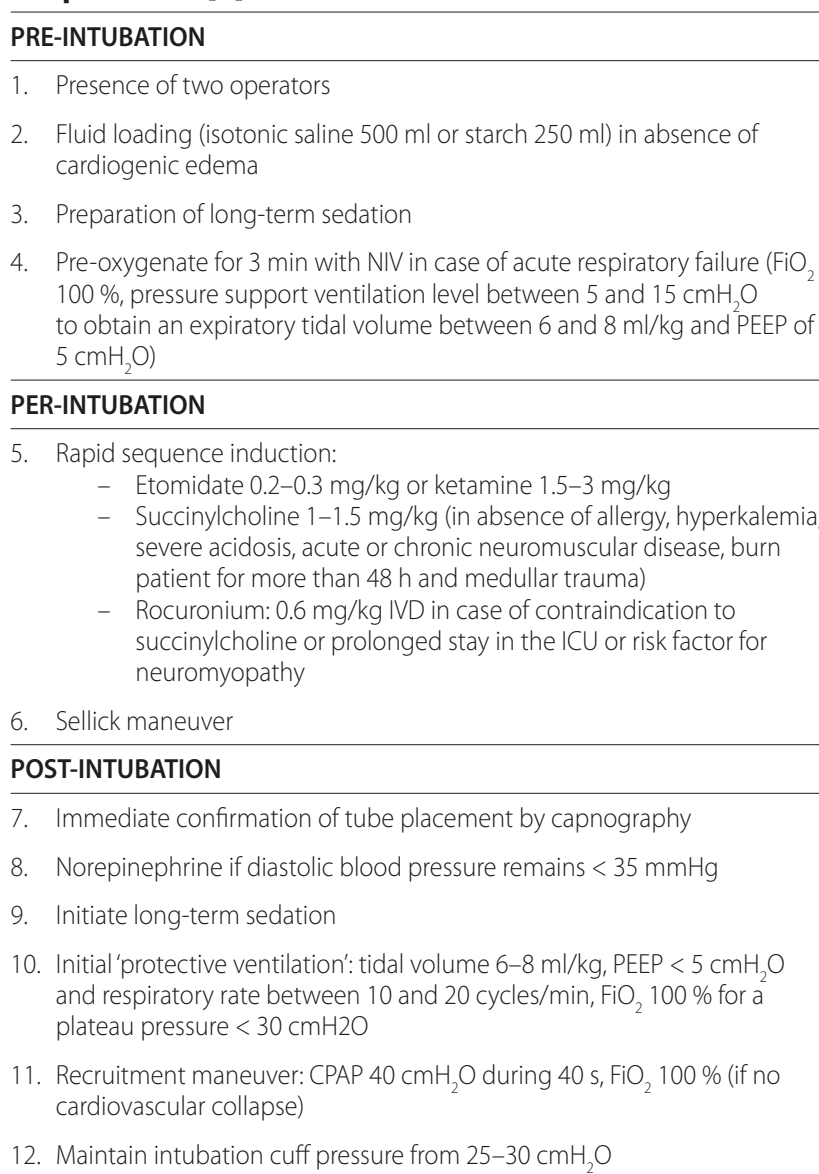

NIV: non-invasive ventilation; CPAP: continuous positive airway pressure ; $\mathrm{FiO}_{2}$ : inspired fraction of oxygen

the ICU, a randomized controlled trial was conducted by our group in 40 critically ill patients requiring intubation for acute hypoxemic respiratory failure [22]. Compared to no RM, an RM performed immediately after intubation was associated with a higher $\mathrm{PaO}_{2}$ (under $100 \% \mathrm{FiO}_{2}$ ) $5 \mathrm{~min}(93 \pm 36$ vs $236 \pm 117 \mathrm{mmHg})$ and $30 \mathrm{~min}(110 \pm 39$ and $180 \pm 79 \mathrm{mmHg}$ ) after intubation.

In the operating room, an initial study assessed the impact of applying several $\operatorname{PEEP}\left(0,5,10 \mathrm{cmH}_{2} \mathrm{O}\right)$ values following intubation in obese and non-obese patients scheduled for surgery [24]. At each step, end-expiratory lung volume, static elastance, gas exchange and dead space were measured. In both obese and non-obese patients, PEEP of $10 \mathrm{cmH}_{2} \mathrm{O}$ compared with zero endexpiratory pressure (ZEEP) improved end-expiratory lung volume and elastance without effects on oxygenation. We then randomized 66 morbidly obese patients (body mass index $46 \pm 6 \mathrm{~kg} / \mathrm{m}^{2}$ ) scheduled for surgery into 3 groups: Conventional pre-oxygenation, pre-oxygenation with NIV and pre-oxygenation with NIV + postintubation RM [23]. The study demonstrated that the 
combination of pre-oxygenation with NIV + postintubation RM helped maintain lung volumes and oxygenation during anesthesia induction more so than pre-oxygenation with either pure oxygen alone or with NIV. One of the main take home messages of this study was that to improve $\mathrm{PaO}_{2} 5$ min after intubation, an $\mathrm{RM}$ added to NIV could be performed. Both oxygenation $\left(\mathrm{PaO}_{2}, 234 \pm 73 \mathrm{mmHg}\right.$ vs $\left.128 \pm 54 \mathrm{mmHg}\right)$ and capnia $\left(\mathrm{PaCO}_{2} 42 \pm 3\right.$ vs $40 \pm 3 \mathrm{mmHg}$ ) were improved in the $\mathrm{RM}+$ NIV group compared to NIV alone.

\section{Bundle to limit complications related to intubation (the Montpellier-ICU intubation algorithm)}

Pre-oxygenation and RMs are only two of the procedures that can improve airway safety. Managing the airway of 'at risk' patients presents some unique challenges for the anesthesiologist/intensivist. The combination of a limited physiologic reserve in these patients and the potential for difficult mask ventilation and intubation mandates careful planning with a good working knowledge of alternative tools and strategies, should conventional attempts at securing the airway fail. Pre-oxygenation techniques can be combined to limit the risk of hypoxia during intubation attempts. To limit the incidence of severe complications occurring after this potentially hazardous procedure, we believe that the whole process (pre-, perand post-intubation) should be guided by protocols geared toward patient safety. We designed a multicenter study and described how implementation of such a bundle protocol could improve the safety of airway management in the ICU [1], [2]. This bundle, the Montpellier-ICU intubation algorithm, is summarized in Table 2.

Briefly, pre-intubation period interventions consisted of fluid loading if there was no cardiogenic edema, preoxygenation with NIV in the case of acute respiratory failure, preparation of sedation by the nursing team and the presence of two operators. NIV applied during the 3-min pre-oxygenation phase was performed with an ICU ventilator (most often those which served to provide invasive mechanical ventilation) and a standard face mask. The PSV level was set between 5 and $15 \mathrm{cmH}_{2} \mathrm{O}$, adjusted to obtain an expired tidal volume of 6 to $8 \mathrm{ml} / \mathrm{kg}$ of ideal body weight. The $\mathrm{FiO}_{2}$ was set at $100 \%$ and we used a PEEP level of $5 \mathrm{~cm} \mathrm{H}_{2} \mathrm{O}$.

During the intubation period, rapid sequence induction (RSI) was recommended using short-acting, well tolerated hypnotics (etomidate or ketamine), and a rapid onset muscle relaxant (succinylcholine), with application of cricoid pressure (Sellick maneuver). The Sellick maneuver was performed to prevent gastric contents from leaking into the pharynx, by external obstruction of the esophagus, and associated inhalation of substances into the lungs, as well as vomiting into an unprotected airway.
Just after the intubation (post-intubation period), we recommended verifying the tube's position by capnography (a technique which allows the endotracheal position of the tube to be confirmed and verifies the absence of esophageal placement), initiation of long-term sedation as soon as possible (to avoid agitation) and use of 'protective' mechanical ventilation settings, as defined by the ARDS network. At any time, vasopressors were mandatory in the event of severe hemodynamic collapse.

\section{Intubation devices: role of videolaryngoscopes in the ICU}

Videolaryngosopes are indirect rigid fiberoptic laryngoscopes with a video camera mounted at the end of an angled blade. The blade is inserted into the mouth in the midline and guided down the back of the tongue until the glottis is visualized. The tip of the endotracheal tube can then be visualized on the video screen and is positioned to enter the glottic inlet. New videolaryngoscope devices are suggested to improve airway management both in anesthesia care and in critically ill patients [25]. In recent years, the role of videolaryngoscopes has been debated, particularly in the ICU where there has been a lack of scientific evidence and generally intubation conditions are more difficult than in the operating room [26]. Recently, however, videolaryngoscopes, such as C-Mac [27], [28] or Glide-scope [29], [30], have demonstrated their effectiveness in the ICU setting. Moreover, a recent study [31] assessed a new mixed videolaryngoscope that can be used as a direct or indirect view laryngoscope. This before-after prospective study showed that the systematic use of a mixed videolaryngoscope for intubation in a quality improvement process using an airway management algorithm significantly reduced the incidence of difficult laryngoscopy and/or difficult intubation. In multivariate analysis, standard laryngoscope use was an independent risk factor for difficult laryngoscopy and/or difficult intubation, as were Mallampati score III or IV and non-expert operator status. Moreover, in the subgroup of patients with difficult intubation predicted by the MACOCHA score [3], incidence of difficult intubation was much higher in the standard laryngoscope group (47\%) than in the mixed videolaryngoscope group (0\%).

In summary, videolaryngoscopes seem to be effective at reducing difficult intubation in ICU patients, but a large multicenter study is needed to assess whether complications of intubation are decreased using videolaryngoscopes.

\section{Airway management algorithm}

As previously recommended in the operating room [32], an airway management algorithm is advised in the ICU (Figure 1). First, the difficulty of intubation is evaluated 


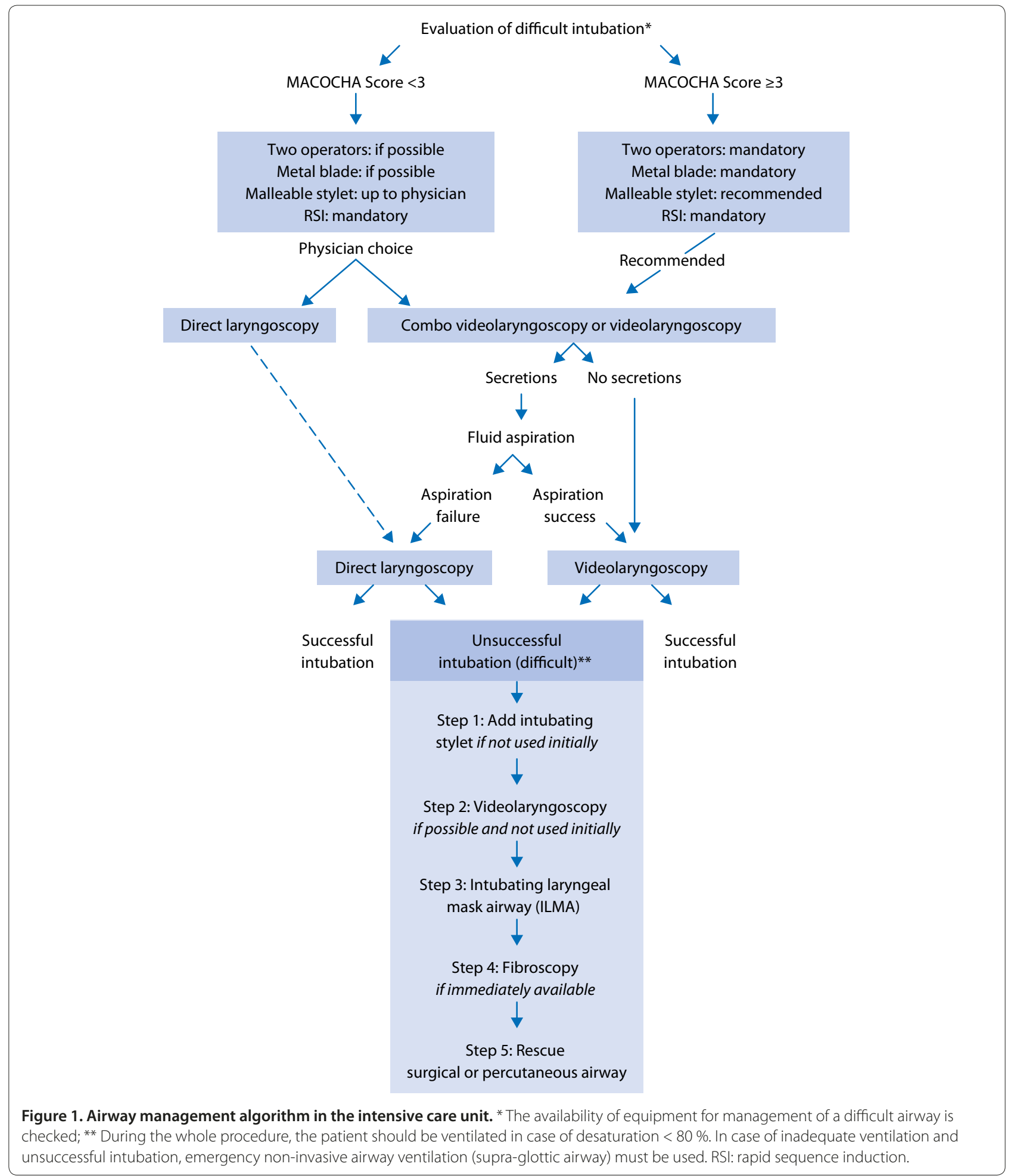

using the MACOCHA score. The availability of equipment for management of a difficult airway is checked. During the procedure, the patient should be ventilated in case of desaturation to $<80 \%$. In case of inadequate ventilation and unsuccessful intubation, emergency non-invasive airway ventilation (supraglottic airway) must be used. If a difficult intubation is predicted (MACOCHA score $\geq 3$ ), the presence of two operators, use of a metal blade, and use of a malleable stylet are recommended. The videolaryngoscopy or combo 
videolaryngoscopy are also recommended in case of predicted difficult intubation. In other cases, choice of the device is at the discretion of the physician. In cases of abundant secretions even after aspiration, direct laryngoscopy is preferred rather than videolaryngoscopy. Finally, in cases of intubation failure, an intubating stylet (malleable stylet or long flexible angulated stylet) should be added first, followed successively by the use of videolaryngoscopy if not initially used, an intubation laryngeal mask airway, fiberoscopy and finally the use of rescue percutaneal or surgical airway.

Studies are needed to assess whether applying this protocol in the ICU enables reduction of difficult intubation and complications. In each ICU, this airway management algorithm could be adapted according to local ICU practice.

\section{Conclusions}

Pre-oxygenation is a standard of care before intubation in the operating room and in the ICU. The aim of preoxygenation is to increase the lungs' stores of oxygen. In the critically ill patient, the combination of pure oxygen, NIV, de-nitrogenation and post-intubation recruitment maneuvers outweighs the potential risk of postintubation atelectasis. Moreover, potential risk factors for difficult intubation should be assessed in ICU patients, in order to identify patients at risk of difficult intubation using a simple score applicable at the bedside. An intubation bundle should then be applied in order to reduce complications of intubation. Finally, an airway management algorithm is strongly advised in the ICU, as in the operating room. In this setting, new intubation devices, such as videolaryngoscopes, should be used after an appropriate training program.

\section{List of abbreviations used}

CPAP: continuous positive airway pressure; $\mathrm{EtO}_{2}$ : end-tidal oxygen concentration; FRC: functional residual capacity; ICU: intensive care unit; IDS: Intubation Difficulty Scale; NIV: non=invasive ventilation; $\mathrm{PAO}_{2}$ : oxygen alveolar pressure; PEEP: positive end-expiratory pressure; PSV: pressure support ventilation; RSI: rapid sequence induction.

\section{Competing interests}

The authors declare that they have no competing interests.

\section{Declarations}

Publication of this article was funded by solely from institutional and departmental sources.

Published: 18 March 2014

\section{References}

1. Jaber S, Amraoui J, Lefrant JY, Arich C, Cohendy R, Landreau L, Calvet Y, Capdevila X, Mahamat A, Eledjam JJ: Clinical practice and risk factors for immediate complications of endotracheal intubation in the intensive care unit: a prospective, multiple-center study. Crit Care Med 2006, 34:2355-2361.

2. Jaber $S$, Jung B, Corne P, Sebbane M, Muller L, Chanques G, Verzilli D, Jonquet O, Eldjam JJ, Lefrant JY: An intervention to decrease complications related to endotracheal intubation in the intensive care unit: a prospective, multiple-center study. Intensive Care Med 2010, 36:248-255.
3. De Jong A, Molinari N, Terzi N, Mongardon, N, Arnal JM, Guitton C, Allaouchiche B, Paugam-Burtz C, Constantin JM, Lefrant JY, Leone M, Papazian L, Asehnoune K, Maziers N, Azoulay E, Pradel G, Jung B, Jaber S, AzuRéa Network for the Frida-Réa Study Group: Early identification of patients at risk for difficult intubation in ICU: Development and validation of the MACOCHA score in a multicenter cohort study. Am J Respir Crit Care Med 2013, 187:832-839.

4. Martin LD, Mhyre JM, Shanks AM, Tremper KK, Kheterpal S: 3,423 emergency tracheal intubations at a university hospital: airway outcomes and complications. Anesthesiology 2011, 114:42-48.

5. Peterson GN, Domino KB, Caplan RA, Posner KL, Lee LA, Cheney FW: Management of the difficult airway: a closed claims analysis. Anesthesiology 2005, 103:33-39.

6. Duggan M, Kavanagh BP: Atelectasis in the perioperative patient. Curr Opin Anaesthesiol 2007, 20:37-42

7. Apfelbaum JL, Hagberg CA, Caplan RA, Blitt CD, Connis RT, Nickinovich DG, Hagberg CA, Caplan RA, Benumof JL, Berry FA, Blitt CD, Bode RH, Cheney FW, Connis RT, Guidry OF, Nickinovich, Ovassapian A: Practice Guidelines for Management of the Difficult Airway: An Updated Report by the American Society of Anesthesiologists Task Force on Management of the Difficult Airway. Anesthesiology 2013, 118:251-270.

8. Tanoubi I, Drolet P, Donati F: Optimizing preoxygenation in adults. Can J Anaesth J Can Anesthésie 2009, 56:449-466.

9. Sum Ping SJT, Makary LF, Van Hal MD: Factors influencing oxygen store during denitrogenation in the healthy patient. J Clin Anesth 2009, 21:183-189.

10. Russell EC, Wrench I, Feast M, Mohammed F: Pre-oxygenation in pregnancy: the effect of fresh gas flow rates within a circle breathing system. Anaesthesia 2008, 63:833-836.

11. Hedenstierna G: Respiratory physiology. In: Miller's anaesthesia Edited by Miller RD, Eriksson LI, Fleisher LA, Wiener-Kronish JP, Young WL (eds). Elsevier, Philadelphia, 2009.

12. Mort TC, Waberski BH, Clive J: Extending the preoxygenation period from 4 to 8 mins in critically ill patients undergoing emergency intubation. Crit Care Med 2009, 37:68-71.

13. Dixon BJ, Dixon JB, Carden JR, Burn AJ, Schachter LM, Playfair JM, Laurie CP $\mathrm{O}$ Brien PE: Preoxygenation is more effective in the 25 degrees head-up position than in the supine position in severely obese patients: a randomized controlled study. Anesthesiology 2005, 102:1110-1115.

14. Altermatt FR, Muñoz HR, Delfino AE, Cortínez LI: Pre-oxygenation in the obese patient: effects of position on tolerance to apnoea. Br J Anaesth 2005, 95:706-709.

15. Ramkumar $V$, Umesh G, Philip FA: Preoxygenation with $20^{\circ}$ head-up tilt provides longer duration of non-hypoxic apnea than conventional preoxygenation in non-obese healthy adults. J Anesth 2011, 25:189-194.

16. Baraka AS, Hanna MT, Jabbour SI, Nawfal MF, Sibai AA, Yazbeck VG, Khoury NI, Karam KS: Preoxygenation of pregnant and nonpregnant women in the head-up versus supine position. Anesth Analg 1992, 75:757-759.

17. Cressey DM, Berthoud MC, Reilly CS: Effectiveness of continuous positive airway pressure to enhance pre-oxygenation in morbidly obese women. Anaesthesia 2001, 56:680-684.

18. Coussa M, Proietti S, Schnyder P, Frasarolo P, Suter M, Spahn DR, Magnusson L: Prevention of atelectasis formation during the induction of general anesthesia in morbidly obese patients. Anesth Analg 2004, 98:1491-1495.

19. Gander S, Frascarolo P, Suter M, Spahn DR, Magnusson L: Positive endexpiratory pressure during induction of general anesthesia increases duration of nonhypoxic apnea in morbidly obese patients. Anesth Analg 2005, 100:580-584

20. Delay J-M, Sebbane M, Jung B, Nocca D, Verzilli D, Pouzeratte Y, Kamel ME, Fabre JM, Eledjam JJ, Jaber S: The effectiveness of noninvasive positive pressure ventilation to enhance preoxygenation in morbidly obese patients: a randomized controlled study. Anesth Analg 2008, 107:1707-1713.

21. Baillard C, Fosse J-P, Sebbane M: Chanques G, Vincent F, Courouble P, Cohen Y, Eledjam JJ, Adnet F, Jaber S: Noninvasive ventilation improves preoxygenation before intubation of hypoxic patients. Am J Respir Crit Care Med 2006, 174:171-177.

22. Constantin JM, Futier E, Cherprenet AL, Chanques G, Guerin R, CayotConstantin S, Jabaudon M, Perbet S, Chartier C, Jung B, Guelon D, Jaber S, Bazin JE: A recruitment maneuver increases oxygenation after intubation of hypoxemic intensive care unit patients: a randomized controlled study. 
Crit Care 2010, 14:R76.

23. Futier E, Constantin JM, Pelosi P, Chanques G, Massone A, Petit A, Kwiatkowski F, BaZIN je, Jaber S: Noninvasive ventilation and alveolar recruitment maneuver improve respiratory function during and after intubation of morbidly obese patients: a randomized controlled study. Anesthesiology 2011, 114:1354-1363.

24. Futier E, Constantin JM, Petit A, Jung B, Kwiatkowski F, Duclos M, Jaber S, Bazin JE: Positive end-expiratory pressure improves end-expiratory lung volume but not oxygenation after induction of anaesthesia. Eur Anaesthesiol 2010, 27:508-513.

25. Asai T: Videolaryngoscopes: do they truly have roles in difficult airways? Anesthesiology 2012, 116:515-517.

26. Cook T, Behringer EC, Benger J: Airway management outside the operating room: hazardous and incompletely studied. Curr Opin Anaesthesiol 2012, 25:461-469

27. Noppens RR, Geimer S, Eisel N, David M, Piepho T: Endotracheal intubation using the $\mathrm{C}-\mathrm{MAC}{ }^{\circledast}$ video laryngoscope or the Macintosh laryngoscope: A prospective, comparative study in the ICU. Crit Care 2012, 16:R103

28. Ng I, Hill AL, Williams DL, Lee K, Segal R: Randomized controlled trial comparing the McGrath videolaryngoscope with the C-MAC videolaryngoscope in intubating adult patients with potential difficult airways. Br J Anaesth 2012, 109:439-443.

29. Kory P, Guevarra K, Mathew JP, Hegde A, Mayo PH: The impact of video laryngoscopy use during urgent endotracheal intubation in the critically ill. Anesth Analg 2013, 117:144-149.
30. Lakticova V, Koenig SJ, Narasimhan M, Mayo PH: Video laryngoscopy is associated with increased first pass success and decreased rate of esophageal intubations during urgent endotracheal intubation in a medical intensive care unit when compared to direct laryngoscopy. $J$ Intensive Care Med 2014 (in press).

31. De Jong A, Clavieras N, Conseil M, Coisel Y, Moury PH, Pouzeratte Y, Cisse M, Belafia F, Jung B, Changues G, Molinari N, Jaber S: Implementation of a Combo video laryngoscope for intubation in critically ill patients. A before-after comparative study. Intensive Care Med 2013, 39:2144-2152.

32. Amathieu R, Combes X, Abdi W, Housseini LE, Rezzoug A, Dinca A, Slavov V, Bloc S, Dhonneur G:An algorithm for difficult airway management, modified for modern optical devices (Airtraq laryngoscope; LMA $\left(\mathrm{Crach}^{\mathrm{T} M}\right)$ : a 2-year prospective validation in patients for elective abdominal, gynecologic, and thyroid surgery. Anesthesiology 2011 , 114:25-33.

doi:10.1186/cc13776

Cite this article as: De Jong A, et al.: Intubation in the ICU: we could improve our practice. Critical Care 2014, 18:209. 